\title{
ORT_24 - Standardization of a Plaque Reduction Test and Evaluation of Neutralizing Antibodies Responses to SARS-CoV-2
}

Ingrid Horbach ${ }^{1 *}$; Adriana de Souza Azevedo Soares ${ }^{1}$; Waleska Dias Schwarcz'; Caio Denani1; Brenda de Moura Dias ${ }^{1}$; Stephanie Almeida da Silva ${ }^{1}$; Bruno Pimenta Setatino ${ }^{1}$; Ivanildo Pedro de Sousa Junior ${ }^{2}$; Sheila Maria Barbosa de Lima ${ }^{1}$.

${ }^{1}$ Fiocruz/Bio-Manguinhos;

${ }^{2}$ Fiocruz/IOC.

Introduction: Two most important forms of diagnostic testing available for SARS-CoV-2 are molecular and serological tests. Among those, the serum neutralization assay stands out as the gold standard for evaluation of the effectiveness of neutralizing antibodies (NAbs) against viral infections. In this regard, it is important the standardization of neutralization-based assay to validate the specificity and sensitivity of current immunoassays against SARS-CoV-2 to avoid bias outcomes.

Objective: The present study aims to develop a test for the evaluation of NAbs against SARSCoV-2 through universal serum neutralization platform by plaque reduction neutralization test (PRNT-SARS-CoV-2).

Methodology: Briefly, 24-well plates were seeded with two different Vero cell concentrations $\left(1.2 \times 10^{5}\right.$ or $2 \times 10^{5}$ cells/well). In addition, dilutions were assessed with approximately 60-100 PFU of SARSCoV-2 (PV004/20 CoV-2-P4; 1,71 X $10^{6}$ TCID50/mL) per well, and plates with virus and serum as well as mock plates followed by incubation at $37^{\circ} \mathrm{C}$ for $1 \mathrm{~h}$. Thereafter, the supernatant was transferred to definitive plates with cell monolayers and incubated at $37^{\circ} \mathrm{C}$ for $1 \mathrm{~h}$. After this time, media was discarded; cells were overlaid with $1 \mathrm{~mL}$ of E199 medium with 1.5 or $2 \%$ of CMC and incubated for 3 days at $37^{\circ} \mathrm{C}$ in $5 \% \mathrm{CO} 2$. Cells were then fixed with $10 \%$ formalin, stained with crystal violet and plaques were counted. Neutralizing antibody titers were expressed by $50 \%$ or $90 \%$ of plaque reduction.

Results: We found that $2 \times 105$ cells/well and $1.5 \%$ of CMC, besides the 1:12.000 of virus dilution revealed to be the better conditions to perform the assay. Our early results showed that the majority of specimens from COVID-19 positive donor presented low neutralizing antibodies levels (Median 1:36.5; titers calculated by reciprocal dilution).

Conclusion: In perspective, this project aims to contribute to elucidate the role of NAb levels in the protection and/or severity of COVID-19. Considering that SARS-CoV-2 infection is a public health concern, besides the imminent vaccination, the available of a neutralization assay, standardized and validated, could help to answer important gaps related to epidemiologic perspective on surveillance policies. The authors thank the Multi-user Research Facility of Biosafety Platform NB3-HPP, Oswaldo Cruz Institute, Oswaldo Cruz Foundation, Rio de Janeiro, Brazil.

Keywords: PRNT; SARS-CoV-2; neutralizing antibodies 